\title{
Differences in Moral Reasoning Among Medical Graduates Compared With Graduates of Other Degrees and Adults Without Professional Degrees
}

\section{Maria Guadalupe Jean-Tron}

Hospital Infantil de México Federico Gómez

Diana Ávila-Montiel

Hospital Infantil de México Federico Gómez

Horacio Márquez-González

Hospital Infantil de México Federico Gómez

Gina del Carmen Chapa-Koloffon

Hospital Infantil de México Federico Gómez

José Antonio Orozco-Morales

Hospital Infantil de México Federico Gómez

Aidee Viridiana Ávila-Hernández

Hospital Infantil de México Federico Gómez

Oscar Valdes-Pérez

Hospital Infantil de México Federico Gómez

Juan Garduño-Espinosa ( $\nabla$ dilemasmorales20@gmail.com )

Hospital Infantil de México Federico Gómez

\section{Research Article}

Keywords: Moral, reasoning, students, medicine students

Posted Date: October 7th, 2021

DOI: https://doi.org/10.21203/rs.3.rs-936255/v1

License: (1) (1) This work is licensed under a Creative Commons Attribution 4.0 International License. Read Full License 


\section{Abstract}

Background. When we talk about morality, a question arises as to whether it is a natural characteristic of humans-that is, whether it is what people should pursue as individuals or whether it is a social construct. Kohlberg established six progressive stages of moral judgment that form three levels of moral development, showing the development of people's thinking on moral issues that is characterized by the aforementioned criteria.

Methods. This study's objective was to compare the level of moral reasoning among graduate students in medicine with a group of young graduates from other degrees and a group of non-professional adults.

The moral reasoning questionnaire (Defining Issues Test, DIT) designed by James Rest based on Kohlberg's theory (Rest 1979) was applied. In total, 304 questionnaires were completed.

Results. Depending on the population studied, differences have been found in the profile of moral development. The profile of family clinic users showed a very high predominance of subjects in category 1 at $70 \%$, but only $4.5 \%$ in category 3 , while in the group of pediatric specialty students, $37.5 \%$ were found in category 1 and $34 \%$ in category 3 . They were the group with the highest percentage in this category. This vast difference could be because the differences in the age and socio-education levels of the beneficiaries are much wider than that of the residents. However, differences are also found if the profiles of residents are compared with those of master's students because the latter comprised $56 \%$ in category 1 and $19 \%$ in category 3 . We also found differences in the profiles of moral development based on the highest education level.

Conclusions. Based on the results of this study, the population could be classified into three levels of moral development, the first level being the predominant one and the third the least common, as we expected prior to the study. The reason why some individuals reach the highest level while others do not remains a question to be addressed. The results show us that there is a difference in some populations depending on education level and even the type of degree pursued.

\section{Background}

When we talk about morality, a question arises as to whether it is a natural characteristic of humans-that is, whether it is what people should pursue as individuals or whether it is a social construct. ${ }^{1}$ While studying the origin and universality of the nature of the mind, it has been assumed that mental functions have a biological basis specific to human beings, which makes all members of the species share certain characteristics with regard to the potential and development of moral reasoning. ${ }^{2,3}$

Kohlberg's evolutionary cognitive development approach suggests that morality is not simply the result of unconscious processes (superego) or early learning (conditioning, reinforcement, and punishment) but that there are some universal moral principles that are not learned in early childhood and are the product of mature rational judgment. ${ }^{4,6,7}$ Kohlberg's special contribution to moral psychology has been the 
application of Piaget's developmental staging scheme in studying the thinking behind how moral judgment evolves in individuals. Moral judgment is understood as a process that allows us to reflect on our values and order them in a logical hierarchy, especially when faced with a moral dilemma. "The exercise of morality is not limited to rare moments in life; it is integral to the thought process we employ to extract meaning from the moral conflicts that arise in daily life." 4,5

Kohlberg established six progressive stages of moral judgment that form three levels of moral development, showing the development of people's thinking on moral issues that is characterized by the aforementioned criteria. The levels of moral development represent different perspectives that a person can adopt in relation to the moral norms of society. Therefore, they constitute three different types of relationships between the subject, norms, and society's expectations. These three levels are as follows: 6,7

Level I: Preconventional Morality. At this level, the individual makes decisions based on external control. It is divided into two stages. The first is called "punishment/obedience orientation," where people obey established rules to avoid punishment. In the second stage, called "instrumental purpose orientation," people take an action to obtain a reward, which is a purely transactional result.

Level II: Conventional Morality. At this level, individuals consider the expectations of society and laws to make decisions when faced with a moral dilemma. Here individuals have already assumed the previously learned authority figures and made them their own. ${ }^{6,7}$ It is divided into two stages in consecutive order with the previous ones. In stage 3 , interpersonal orientation, individuals seek the approval of "significant others" (in their close environment). In stage 4, law-and-order orientation, individuals are oriented toward authority and try to maintain an already established social order. In this case, laws are the absolute moral engine.

Level III: Principled or Postconventional Morality. At this level, judgments made by individuals are based on abstract and personal principles that are not necessarily defined by the laws of society. Values independent of institutions (e.g., liberty and life) are established and ultimately scaled. ${ }^{6,7}$ In stage 5, social-contract orientation, the correct action is usually defined in terms of the general rights of the people, which have been agreed upon by society through consensus. In stage 6, universal-ethical-principal orientation, correctness is defined by conscientious decisions in accordance with self-chosen ethical principles based on logic, consistency, and universality. Thus, correctness is a matter of individual conscience and involves the abstract concepts of justice, human dignity, and equality.

\section{Methods}

This study's objective was to compare the level of moral reasoning among graduate students in medicine with a group of young graduates from other degrees and a group of non-professional adults. The sample comprised 237 participants: 88 students belonged to the pediatrics specialty from a level three children's hospital; 36 students were from two graduate programs based in the same hospital; 46 young people were enrolled in a social program of the Mexican government; and 67 were beneficiaries of a Family 
Medicine clinic. After the participants agreed to be a part of the study and signed the informed consent letter, two questionnaires were provided to the participants. The first was used to obtain general data, including age, sex, place of residence, religion, monthly income, and other sociodemographic data.

The moral reasoning questionnaire (Defining Issues Test, DIT) designed by James Rest based on Kohlberg's theory (Rest 1979) was applied. In this questionnaire, three stories are presented to the subject, each one describing a moral dilemma. In the first section of answers, subjects were asked their opinion about what the person in the story should do, responding with "yes," "no," or "I cannot decide." In the second section, participants were asked to give their opinion regarding 12 sentences according to the degree of importance. The sentences represent each of Kohlberg's moral stages and present possible resolutions to the dilemma. In the third section, subjects chose the four most important statements from each story based on what was chosen in the second section and ranked them from first to fourth in decreasing order of importance. With these responses, raw and percentage scores were developed to express the frequency with which the subject used one of stages 2-6 of moral reasoning.

The principled moral reasoning index (P score) was also calculated, which expresses the degree to which a person judges these problems from a postconventional perspective. This index was prepared with the scores corresponding to stages 5 and 6 . In the analyses carried out in this work, averages were calculated for each stage and for the $\mathrm{P}$ index. A descriptive analysis was performed for the sociodemographic characteristics of the population. Qualitative variables were reported with total numbers and percentages and quantitative variables with mean and standard deviation.

Moral development profiles were created on the basis of averages and minimum-maximum ranges because not all the groups fulfilled a normal distribution. These averages were calculated for stages $2-6$, as well as for the $\mathrm{P}$ index, dividing each group by the academic program to which they belonged and other variables of interest. Further, the frequencies of each of the $P$ index categories were calculated, both in total and for each variable of interest.

\section{Results}

In total, 304 questionnaires were completed, of which 67 (22\%) questionnaires were removed, leaving a total of 237 questionnaires. Of those removed, 45 were incomplete submissions, 17 had inconsistencies, and 5 exceeded the allowed $\mathrm{M}$ score.

Table 1 describes the baseline characteristics of the final 237 participants. The majority of the sample comprised women. The mean age was 32.5 years. Most of the participants (65\%) were single, and $28 \%$ were married. Of the sample, $66 \%$ reported belonging to some type of religion; however, only $53 \%$ of these were practitioners. The predominant religion was Catholicism with $91 \%$.

Most of the subjects were from Mexico City and the State of Mexico (71\%), 26\% from another state, and $2.5 \%$ from another country. Subjects were asked who they lived with as children. The majority reported having grown up with their parents (85\%). $41 \%$ reported currently living with their family of origin, $23 \%$ 
with their own family, and $17 \%$ lived alone. Most participants had an undergraduate education level (66\%), almost $10 \%$ had completed postgraduate studies, and less than $4 \%$ had completed elementary school studies or lower. With regard to the level of income, $35 \%$ of the subjects reported having income between $\$ 2,700$ and $\$ 6,799$ and $30 \%$ between $\$ 6,800$ and $\$ 11,599$. 
Table 1

Characteristics of the total population and categories by sex

\begin{tabular}{|c|c|c|c|}
\hline & $\begin{array}{l}\text { Total } n=237 \\
\text { TN (\%) }\end{array}$ & $\begin{array}{l}\text { Men } n=72 \\
\operatorname{TN}(\%)\end{array}$ & $\begin{array}{l}\text { Women } \mathrm{n}=165 \\
\mathrm{TN}(\%)\end{array}$ \\
\hline Population Residents Master's & $88(36.8)$ & $27(37.5)$ & $61(37)$ \\
\hline Family clinic & $36(15.1)$ & $12(16.7)$ & $24(14.5)$ \\
\hline Youth from the social program & $67(28)$ & $21(29.2)$ & $46(27.9)$ \\
\hline & $46(19.2)$ & $12(16.7)$ & $34(20.6)$ \\
\hline Age $($ mean $\pm S D)$ & $32.5 \pm 13.3$ & $34.4 \pm 15.8$ & $31.6 \pm 11.9$ \\
\hline Marital Status Single & $156(65.3)$ & $44(61.1)$ & $112(67.9)$ \\
\hline Married or Civil Union & $66(27.6)$ & $24(33.3)$ & $42(25.5)$ \\
\hline Divorced or Separated & $10(4.2)$ & $3(4.2)$ & $7(4.2)$ \\
\hline Widow(er) & $5(2.1)$ & $1(1.4)$ & $4(2.4)$ \\
\hline Religion & $157(65.7)$ & $46(63.9)$ & $111(67.3)$ \\
\hline Type of religion Catholic & $146(91.3)$ & $42(89.4)$ & $104(92)$ \\
\hline $\begin{array}{l}\mathrm{n}=157 \\
\text { Christian }\end{array}$ & $10(6.3)$ & $3(6.4)$ & $7(6.2)$ \\
\hline Not specified & $4(2.5)$ & $2(4.3)$ & $2(1.8)$ \\
\hline Practice religion $n=157$ & $85(53.1)$ & $28(59.6)$ & $57(50.4)$ \\
\hline Place of Birth Mexico City & $141(59)$ & $38(52.8)$ & $103(62.4)$ \\
\hline Mexico state & $28(11.7)$ & $7(9.7)$ & $21(12.7)$ \\
\hline Another state & $62(25.9)$ & $26(36.1)$ & $36(21.8)$ \\
\hline Another country & $6(2.5)$ & $1(1.4)$ & $5(3)$ \\
\hline Place of residence Mexico City & $203(84.9)$ & $63(87.5)$ & $140(84.8)$ \\
\hline Mexico state & $34(14.2)$ & $9(12.5)$ & $25(15.2)$ \\
\hline Childhood home family members Parents & $202(84.5)$ & $63(87.5)$ & $139(84.2)$ \\
\hline Father or mother & $24(10)$ & $7(9.7)$ & $17(10.3)$ \\
\hline Extended family & $9(3.8)$ & $2(2.8)$ & $7(4.2)$ \\
\hline Other family & $2(0.8)$ & 0 & $2(1.2)$ \\
\hline
\end{tabular}




\begin{tabular}{|c|c|c|c|}
\hline & $\begin{array}{l}\text { Total } n=237 \\
\text { TN (\%) }\end{array}$ & $\begin{array}{l}\text { Men } \mathrm{n}=72 \\
\operatorname{TN}(\%)\end{array}$ & $\begin{array}{l}\text { Women } \mathrm{n}=165 \\
\mathrm{TN}(\%)\end{array}$ \\
\hline Current household family members & $99(41.4)$ & $26(36.1)$ & $73(44.2)$ \\
\hline Family of origin & $55(23)$ & $17(23.6)$ & $38(23)$ \\
\hline Own family & $43(18)$ & $14(19.4)$ & $29(17.6)$ \\
\hline Alone & $40(16.7)$ & $15(20.8)$ & $25(15.2)$ \\
\hline Education level Primary school & $9(3.8)$ & $5(6.9)$ & $4(2.4)$ \\
\hline Middle school & $22(9.2)$ & $4(5.6)$ & $18(11)$ \\
\hline High School & $25(10.5)$ & $6(8.3)$ & $19(11.6)$ \\
\hline Undergraduate & $157(65.7)$ & $48(66.7)$ & $109(66.5)$ \\
\hline Graduate & $23(9.6)$ & $9(12.5)$ & $14(8.5)$ \\
\hline Monthly income 0-2,699 & $32(13.4)$ & $12(16.7)$ & $20(12.1)$ \\
\hline $2,700-6,799$ & $84(35.1)$ & $16(22.2)$ & $68(41.2)$ \\
\hline $6,800-11,599$ & $71(29.7)$ & $25(34.7)$ & $46(27.9)$ \\
\hline $11,600-34,999$ & $39(16.3)$ & $13(18.1)$ & $26(15.8)$ \\
\hline More than 35,000 & $11(4.6)$ & $6(8.3)$ & $5(3)$ \\
\hline
\end{tabular}

\section{Results Of The Development Of Moral Reasoning}

Table 2 shows the results of the development of moral reasoning through the DIT for both the total number of participants and categories by sex. The score increases in the first stages until a higher score is obtained for stage 4 , with an average of 36.9 , with no difference between sexes, and with a decrease in the score as the stages go up. The $P$ index showed an average of 29.2, noting a difference of almost 7 points between the sexes, favoring women.

Additionally, the P index (CatP) was categorized into terciles: Category 1 corresponds to the lowest stages (preconventional) -that is, scores less than 30 points; category 2, to the middle stages (conventional)that is, scores between 30 and 39.9 points; and category 3, to the highest stages (postconventional) -that is, scores greater than 40 points. A total of $53 \%$ of the population was found in category $1,25 \%$ in category 2 , and only $21 \%$ in category 3 . Regarding sex, there were some differences because $64 \%$ of men 
were in category 1 , and only $17 \%$ were in category 3 , while for women, $49 \%$ were in category 1 , and $23 \%$ in category 3 (Table 2).

Table 2

Average and minimum-maximum range of stages $2-6$ and the total $\mathrm{P}$ index and categories by sex. Frequencies of total P-index categories and categories by sex

\begin{tabular}{|llll|}
\hline Stage & $\begin{array}{l}\text { Total } n=237 \\
\text { Av. }(\text { min-max })\end{array}$ & $\begin{array}{l}\text { Men } n=72 \\
\text { Av. }(\text { min-max })\end{array}$ & $\begin{array}{l}\text { Women } n=165 \\
\text { Av. (min-max) }\end{array}$ \\
\hline 2 & $6.1(0-26.6)$ & $6.6(0-26.6)$ & $3.3(0-26.6)$ \\
\hline 3 & $17.3(0-53.3)$ & $16.6(0-46.7)$ & $16.6(0-53.3)$ \\
\hline 4 & $36.9(0-80)$ & $36.7(0-80)$ & $36.6(0-70)$ \\
\hline $5 A$ & $17.4(0-56.6)$ & $15(0-43.3)$ & $16.6(0-56.6)$ \\
\hline $5 B$ & $5.6(0-13.6)$ & $0(0-13.3)$ & $6.6(0-13.6)$ \\
\hline 6 & $6.5(0-20)$ & $3.3(0-20)$ & $6.7(0-20)$ \\
\hline P index & $29.2(3.3-83.3)$ & $23.3(3.3-63.3)$ & $30(3.3-83.3)$ \\
\hline Cat P 1 & $126(52.7)$ & $46(63.9)$ & $80(48.5)$ \\
\hline TN (\%) 2 & $61(25.5)$ & $14(19.4)$ & $47(28.5)$ \\
\hline 3 & $50(20.9)$ & $12(16.7)$ & $38(23)$ \\
\hline Note: TN: total numbers & & \\
\hline
\end{tabular}

For our main objective, different study populations were considered-that is, medical graduate students, graduates of other degrees, and people without a full degree or a lower educational level, belonging to the population of UMF 31. Table 3 describes the development profile of moral reasoning according to these populations. A higher $\mathrm{P}$ index score was observed among pediatric specialty students (33.3) compared to the other populations. The family clinic population obtained the lowest score with 20 points. The same is observed with the $\mathrm{P}$ score categories, considering that within the group of specialty students, $36 \%$ were in category 3 , and only $4.5 \%$ were in the clinic group. 
Table 3

Average and minimum-maximum range of stages $2-6$ and the total $P$ index and categories per population. Frequencies of total $\mathrm{P}$ index categories and categories by population.

\begin{tabular}{|c|c|c|c|c|c|}
\hline Stages & $\begin{array}{l}\text { Total } n=237 \\
\text { Av. (min-max) }\end{array}$ & $\begin{array}{l}\text { Residence } \mathrm{n}= \\
88 \\
\text { Av. (min-max) }\end{array}$ & $\begin{array}{l}\text { Master's degree } \\
\mathrm{n}=36 \\
\text { Av. (min-max) }\end{array}$ & $\begin{array}{l}\text { UMF } 31 \\
n=67 \\
\text { Av. (min- } \\
\text { max) }\end{array}$ & $\begin{array}{l}\text { JCF } \\
n=46 \\
\text { Av. (min-max) }\end{array}$ \\
\hline 2 & $6.1(0-26.6)$ & $4.9(0-23.3)$ & $8.4(0-20)$ & $3.3(0-26.6)$ & $3.3(0-26.6)$ \\
\hline 3 & $17.3(0-53.3)$ & $13.3(0-53.3)$ & $18.4(0-50)$ & $16.6(0-43.3)$ & $20(3.3-46.6)$ \\
\hline 4 & $36.9(0-80)$ & $36.6(0-80)$ & $\begin{array}{l}36.7(13.3- \\
63.3)\end{array}$ & $36.6(0-70)$ & $\begin{array}{l}33.3(6.6- \\
63.6)\end{array}$ \\
\hline $5 \mathrm{~A}$ & $17.4(0-56.6)$ & $20(0-56.6)$ & $15(0-36.7)$ & $13.3(0-36.6)$ & $16.6(0-56.6)$ \\
\hline $5 B$ & $5.6(0-13.6)$ & $10(0-13.3)$ & $10(0-13.3)$ & $0(0-13.3)$ & $6.6(0-13.6)$ \\
\hline 6 & $6.5(0-20)$ & $6.7(0-20)$ & $6.7(0-20)$ & $6.6(0-20)$ & $4.9(0-16.6)$ \\
\hline$P$ index & $\begin{array}{l}29.2(3.3- \\
83.3)\end{array}$ & $33.3(3.3-76.6)$ & $26.7(3.3-53.3)$ & $20(3.3-50)$ & $26.6(10-83.3)$ \\
\hline Cat P 1 & $126(52.7)$ & $33(37.5)$ & $20(55.6)$ & $47(70.1)$ & $26(56.5)$ \\
\hline $\begin{array}{l}\text { NT (\%) } \\
2\end{array}$ & $61(25.5)$ & $23(26.1)$ & $9(25)$ & $17(25.4)$ & $12(26.1)$ \\
\hline 3 & $50(20.9)$ & $32(36.4)$ & 7 (19.4) & $3(4.5)$ & $8(17.4)$ \\
\hline
\end{tabular}

This same analysis was conducted for other variables of interest. Considering the participants' education level, the average P score increases as the highest level of studies progresses, with primary school studies being 16.6; middle school studies, 21.7; high school studies, 20; and reaching an undergraduate degree, 30. Subsequently, a slight decrease was noted in the postgraduate participants with a $P$ index of 26.7. The same is true for the Cat $P$ categories, with $89 \%$ of participants with only primary school education, $72 \%$ with high school education, and only $47 \%$ with a bachelor's degree in category 1 . In contrast, in category 3 , there were no participants with primary or middle school education; $12 \%$ had high school education, with the scores increasing in those with undergraduate degrees $(27 \%)$ and decreasing in those with postgraduate degrees (17\%).

Considering whether the participant reported belonging to a religion or not, the $\mathrm{P}$ index did not show differences, with 26.7 for those who belonged to a religion and 26.6 for those who did not. Those who did belong to a religion (157 subjects) were asked whether or not they frequently practiced their religion. The $P$ index of those who did not practice it was 30 points while those who did practice it was 26.6. Of those who did, $58 \%$ were in category $1,27 \%$ in category 2 , and $15 \%$ in category 3 . Of those who did not, $42 \%$ were in category $1,35 \%$ in category 2 , and $23 \%$ in category 3. 


\section{Discussion}

In the present study, the moral development profile of different populations with different education and social levels is presented. The moral development profile of the total population studied shows growth from stages 2 to stage 4 with a predominance of the latter, while the later decreased in the highest stages (5 and 6). This same profile was reported by other authors. ${ }^{8,9,10}$ This predominance of stage 4 corresponds to a conventional level-that is, the norm-keeping scheme of Kolhberg's theory of moral development. The average $P$ index score of the population was 29.2, which is similar to other studies in the Mexican population. In a group of upper-level students, Barba found an average $P$ index of 25.9, finding that students older than 21 years had a higher $P$ index of 28.2 compared to younger students, who had around 24.1 points. Further, middle school students obtained a lower $\mathrm{P}$ index, approximately 21.1 , indicating that age and academic level could influence moral reasoning. ${ }^{11,12}$

We evaluated the DIT results in a different way, so we categorized the population into terciles based on the $\mathrm{P}$ index. Category one is the lowest level of moral development, which corresponds to preconventional levels 1 and 2 and conventional level 3 of Kolhberg's theory. Category 2 is the medium level, which corresponds to the conventional level 4 of Kolhberg's theory, and category 3 is the high level of moral development, which corresponds to the postconventional levels (5 and 6 ) of Kolhberg's theory. With this in mind, the population studied showed a clear predominance of category 1 with almost $53 \%$, while only $21 \%$ of the participants fell into category 3 .

We found differences when observing these results with the sex variable because women showed a higher percentage in category 3 with $23 \%$, compared to $17 \%$ of men. Men had a higher percentage in category 1 with $64 \%$, compared to women with $49 \%$. This could contradict Kolhberg, ${ }^{13}$ who noted that men tend to use more principled reasoning (postconventional reasoning) than women. However, different empirical studies have shown the opposite, such as Barba in his 2003 and 2005 studies $^{11,12}$, which corresponds to our findings.

Depending on the population studied, differences have been found in the profile of moral development. The profile of family clinic users showed a very high predominance of subjects in category 1 at $70 \%$, but only $4.5 \%$ in category 3 , while in the group of pediatric specialty students, $37.5 \%$ were found in category 1 and $34 \%$ in category 3 . They were the group with the highest percentage in this category. This vast difference could be because the differences in the age and socio-education levels of the beneficiaries are much wider than that of the residents. However, differences are also found if the profiles of residents are compared with those of master's students because the latter comprised $56 \%$ in category 1 and $19 \%$ in category 3.

We also found differences in the profiles of moral development based on the highest education level. With regard to the percentage of subjects in category 1 , it seems to be higher the lower the subject's education level, with $89 \%$ in subjects with primary school education, $68 \%$ with middle school education, $72 \%$ with high school education, $47 \%$ with undergraduate degrees, and $52 \%$ with postgraduate degrees. In 
contrast, the percentage of subjects in category 3 seems to increase based on a higher education level, with $0 \%$ in primary and secondary schools, $12 \%$ in middle school, $27 \%$ pursuing undergraduate degrees. Among participants with graduate degrees, this percentage decreases to $17 \%$. The largest number of subjects in category 3 is from the group of those with an undergraduate degree. However, most of them belong to the group of pediatric residents, of whom we previously showed had presented the highest percentage of this category. Therefore, it could be assumed that not only the education level but also the type of career pursued has an influence; this can be the object of further research.

We also evaluated the religion variable, without finding differences in the profile of moral development between those who reported belonging to a religion and those who did not. However, we did find slight differences between those who practiced their religion and those who did not, with a greater number of participants in category 3 within the non-practicing group (23\%) than in that of practitioners (15.3\%). This could correspond to the fact that the practitioners of a religion tend to have a greater development of conventional moral reasoning because they tend to make decisions based on the norms dictated by their religion.

\section{Conclusions}

With regard to the limitations of the study, the number of subjects for each of the three populations is highly variable, so they are not fully comparable. Therefore, a descriptive study was conducted to explore some differences that may exist. The recruitment of the subjects was based on convenience, so representativeness to other types of populations cannot be assured.

Based on the results of this study, the population could be classified into three levels of moral development, the first level being the predominant one and the third the least common, as we expected prior to the study. The reason why some individuals reach the highest level while others do not remains a question to be addressed. The results show us that there is a difference in some populations depending on education level and even the type of degree pursued. Finding differences between subjects with a degree, depending on their chosen career, makes us think that certain characteristics of these subjects make them advance more or less in their moral development. These characteristics could have been obtained by studying in their field or because of characteristics of the subject's personality, as well as from previous experiences, so these results open the path to new research on the causes that lead to a high level of moral development. We also found that women tend to have a higher level of moral development.

\section{Abbreviations}

DIT

Defining Issues Test

UMF

Family Medicine Clinic 
JCF

Young people were enrolled in a social program of the Mexican government

Av

Average

TN

Total Numbers

\section{Declarations}

\section{Ethics approval and consent to participate}

All methods were carried out in accordance with relevant guidelines and regulations. Ethics approval for this study entitled "Profile of moral reasoning development in a sample of Mexico City residents" was granted by the Comité de Ética en Investigación del Hospital Infantil de México Federico Gómez, with register number CONBIOÉTICA-09-CEI-010-20160627. Participants read and signed consent forms prior to participating in the study and consent for publication.

\section{Consent for publication}

Participants read and signed consent forms prior to participating in the study and consent for publication.

\section{Availability of data and materials}

Data are available in Excel format on request.

\section{Competing interests}

The authors declare that they have no competing interests

\section{Funding}

No funds required

\section{Authors' contributions}

MGJT, JGE conceptualized the paper. MGJT, JGE and HMG drafted the paper. MGJT and HMG statistical analysis. DAM: literature review. GCCK, JAOM, AVAH, OVP conducted the fieldwork.

All authors read and approved the final version of the manuscript.

\section{Corresponding author}

Correspondence to Juan Garduño-Espinosa 
Acknowledgements

The authors want to thank the Education Directorate of this Health Institute for their interest in the subject and for providing the conditions required to conduct it. We also what to thank Dr. Barba for sharing with us an adaptation of DIT questionnaire in Spanish.

\section{References}

1. Fleischacker S. The ethics of culture. Ithaca, NY: Cornell University Press; 1994.

2. Henrich J, Heine SJ, Norenzayan A. The weirdest people in the world? Behav Brain Sci. 2010;33:6183; discussion 83. doi: 10.1017/S0140525X0999152X, PMID 20550733.

3. Norenzayan A, Heine SJ. Psychological universals: what are they and how can we know? Psychol Bull. 2005;131:763-84. doi: 10.1037/0033-2909.131.5.763, PMID 16187859.

4. Hers R, Reimer R, Paolitto D. El crecimiento moral [Moral growth]. De Piaget a Kohlberg. 4th ed; 2002.

5. Piaget J. The moral judgment of the child. New York: Free Press; 1932.

6. Kohlberg L. Moral stages and moralization: the cognitive-development approach. In: Likonij T, editor, Moral development and behavior: theory, research, and social issues. New York: Holt, Rinehart \& Winston; 1976.

7. Kohlberg L. The psychology of moral development: the nature and validity of moral stages. 1 st ed. New York: HarperCollins; 1984.

8. Bohm KC, Van Heest T, Gioe TJ, Agel J, Johnson TC, Van Heest A. Assessment of moral reasoning skills in the orthopaedic surgery resident applicant. J Bone Joint Surg Am. 2014;96. doi: 10.2106/JBJS.M.00706, PMID 25187595.

9. Roche $\mathrm{C}$, Thoma $\mathrm{S}$. Insights from the defining issues test on moral reasoning competencies development in community pharmacists. Am J Pharm Educ. 2017;81:5913. doi: 10.5688/ajpe5913, PMID 29200446.

10. Batchelor CEM, Creed A, McKeegan DEF. A preliminary investigation into the moral reasoning abilities of UK veterinarians. Vet Rec. 2015;177:124. doi: 10.1136/vr.102775, PMID 26109285.

11. Barba B. Razonamiento moral de principios en estudiantes de secundaria y bachillerato [Principled moral reasoning in middle and high school students]. Rev Mex Investig Educ Mex. 2001;3:21-5.

12. Barba B, Matías-Romo J. Desarrollo del Juicio moral en la educación superior [Development of moral judgment in higher education]. Rev Mex Investig Educ, México (Ene-marzo). 2005;10:67-92.

13. Sachdeva S, Singh P, Medin D. Culture and the quest for universal principles in moral reasoning. Int J Psychol. 2011;46:161-76. doi: 10.1080/00207594.2011.568486, PMID 22044230. 